has been demonstrated that nitroglycerin is more effective than calcium blockers to relieve spasm. Today we are using nitroglycerin intravenously, and in the first weeks we are still giving calcium blockers, but I think that this aspect is not the most important issue for the patency rate of the RA. I think that the technical aspect and the choice of the correct territory is the key point for the satisfying patency rate. The pharmacologic aspect becomes less important.

Dr Brian Buxton (Heidelberg, Australia). You are a few years ahead of us with the number of RA grafts and ITA grafts that you have been performing. I have the impression that the RA does not quite match up to the free RITA, although your results here suggest that they do. If you had a crystal ball, what would you think would happen over an extended period of time?

Do you think it is just as valid to use an RA as the Y graft component, or do you think that there is still a very important role for Dr Tector's operation, in which the RITA is attached to the side of the LITA? In other words, do you think there is any difference? I know you show there is none.

Dr Calafiore. I think that today the best operation always is to use the 2 thoracic arteries, perhaps in the $\mathrm{Y}$ or $\mathrm{T}$ graft, as Dr Tector proposed. But what I think is important is the message that the RA is a second arterial conduit that can be used with very good results. I think that many surgeons will use a second conduit if this is an
RA because it has a good size and can be harvested contemporaneously with the LITA. Many surgeons will not use the RITA every day in every patient. Today my policy is still to use 2 thoracic arteries for the great majority of patients. However, I think that the knowledge that the patency rate of the RA in selected cases is pretty good is important information and a positive message to send.

Dr O. Wayne Isom (New York, NY). There was one thing you did not mention. Did you notice, in the patients with bilateral ITA harvesting, any increase in sternal infection?

Dr Calafiore. In 1994 and 1995 we completely changed the method of dissecting ITAs that were skeletonized during harvesting. It was demonstrated, both in necropsies and studying the sternal vascularization after bilateral ITA harvesting, that the skeletonization preserves the sternum from the devascularization that follows the harvesting of both ITAs. We used a lot of RAs in the first part of our experience because the RITA was not used in diabetic patients. Now we are using the RITA in all the patients who have so-called risk factors such as obesity and diabetes.

Dr Isom. You do not notice any difference in infection?

Dr Calafiore. No. There is no difference in the infection rate or in the major sternal problems in patients with 1 or 2 ITAs if skeletonized.

\title{
Notice from the American Board of Thoracic Surgery regarding trainees and candidates for certification who are called to military service related to the war on terrorism
}

The Board appreciates the concern of those who have received emergency call to military service. They may be assured that the Board will exercise the same sympathetic consideration as was given to candidates, in recognition of their special contributions to their country, during the Viet Nam conflict and the Persian Gulf conflict with regard to applications, examinations, and interruption of training. If you have any questions about how this might affect you, please call the Board office at 847-475-1520.

Peter C. Pairolero, MD

Chair

The American Board of Thoracic Surgery 